\title{
Expectativas e Desafios: Learning Analytics em MOOC
}

\author{
Patricia Grasel da Silva ${ }^{1}$, Marie Jane Soares Carvalho ${ }^{2}$, Adriano Canabarro \\ Teixeira $^{3}$ \\ ${ }^{1}$ Departamento de Informática - Instituto de Federal do Rio de Janeiro (IFRJ) \\ Campi São João de Meriti - Rio de Janeiro - RJ - Brazil \\ ${ }^{2}$ Departamento de Educação - Universidade Federal do Rio Grande do Sul (UFRGS) \\ Campus Centro - Porto Alegre - RS - Brazil \\ ${ }^{3}$ Departamento de Informática - Universidade de Passo Fundo (UPF) \\ Campus Central - Passo Fundo - RS - Brazil \\ patricia.graseleifrj.edu.br, marie.janedufrgs.br, teixeiradupf.br
}

Abstract.The article deals with learning in the Massive Open Online Course $(M O O C)$. The objective was to identify the interactions that emerge from the social exchanges established among students through written communication. To do so, we analyze students' postings in discussion forums, within a pedagogical proposal of MOOC. The methodology is configured as a qualitative-quantitative research, which was based on approximately 4,000 people enrolled, which contributed to the method of analysis of social networks (ARS) and data mining. In the study conducted, it was identified that the social exchanges established within the MOOC are minimal due to the size of the reach of the content and the expressive number of students enrolled.

Resumo.O artigo trata sobre aprendizagens em Massive Open On-line Course (MOOC). Objetivo foi identificar interações que emergem das trocas sociais estabelecidas entre os alunos, através da comunicação escrita. Para tanto, analisamos postagens dos alunos em fóruns de discussões, dentro de uma proposta pedagógica de um MOOC específico. A metodologia configura-se como uma pesquisa quali-quantitativa, que teve como cenário aproximadamente 4.000 pessoas matriculadas, o que contribuiu para método de análise de redes sociais (ARS) e de mineração de dados. No estudo realizado identificou-se que as trocas sociais estabelecidas dentro do MOOC são mínimas diante da dimensão do alcance do conteúdo e do número expressivo de alunos matriculados, o que revela um desafio a personal learning em tempos de cultura digital.

\section{O que são MOOCs}

A cultura digital presente na sociedade atual tem nos Massive Open On-line Course (MOOC) mais uma possibilidade disseminação da informação, os cursos massivos abertos e online são mais uma oportunidade de estudo para além do espaço formal e 
VII Congresso Brasileiro de Informática na Educação (CBIE 2018)

Anais dos Workshops do VII Congresso Brasileiro de Informática na Educação (WCBIE 2018)

presencial de ensino. São cursos organizados em plataformas digitais, que disponibilizam materiais em diferentes mídias, que servem para formação continuada ou para estudo específico de conteúdo.

MOOC surgiu na época do ano 2000, teve seu reconhecimento mundial em 2012, ano que foi chamado "ano dos MOOCs". A pesquisas referente aos cursos são sobre questões procedimentais: design, plataformas, produção de materiais entre outros. Há carência de estudos sobre learning analytics em cursos com características de massivos, abertos e on-line. São identificados através do compartilhamento de informação e conteúdo de forma rápida, maior número de sujeitos envolvidos e perfil do aluno com ênfase na autonomia e organização do tempo. PISUTOVA (2012) destaca como característica o engajamento ativo de um número significativo (massivo) de pessoas que auto-organizam sua participação, de acordo com seus interesses em comum, normalmente são gratuitos e alguns exigem pagamento apenas para certificação, sendo suas principais características: ser aberto, gratuito, colaborativo e distribuído.

\section{Learning em MOOC}

O conteúdo de MOOC por ser aberto e on-line pode ser objeto de discussão e estudo, através do compartilhamento em outros espaços, que não necessariamente a plataforma institucional do curso. Uma das possibilidades do conteúdo em rede digital é justamente a facilidade de disseminar a informação, através do ato de postar, compartilhar, curtir, comentar. A ação nunca é vazia, traz consigo a representação de significados do sujeito com objeto de conhecimento (conteúdo) e podem desencadear reações.

Ao considerar comportamentos emergentes de uma cultura digital dentro do MOOC, é necessário interpretar o significado de cada ação, pois cada ato do sujeito em rede gera implicações. O que pode ser melhor compreendido através da teoria de Barabási (2009) que fala: na rede não há fatos isolados, eles influenciam ou são influenciados. Visualizar não representa necessariamente concordar com o que foi publicado, compartilhar uma postagem pode ter significados como concordar, chamar atenção, mostrar que está ciente ou até mesmo revelar um pertencimento a um grupo e/ou uma comunidade. Comentar pode ser compreendido como autonomia da opinião, postar pode provocar ao sujeito autor do post um sentimento de ser ouvido/lido, ser uma voz na rede. Quando falamos em construção de conhecimento através dos recursos digitais, todas essas ações devem ser objeto de observação, pois implicam na learning analytics.

Ações de trocas on-line ganham dimensão de percepção, principalmente, nas redes sociais, o compartilhamento de informação está baseado nas formas de comunicação, que hoje são potencializadas pelos dispositivos móveis conectados à internet. Trocar com outro pode revelar um processo de auto-organização do sujeito sobre seu processo de acesso à informação, trata-se de mais uma forma de se manter informado, obter informação através das conexões estabelecidas. Estar informado sobre suas conexões e sobre as conexões das suas conexões, estar ciente sobre o conteúdo que está transitando em rede, são ações do sujeito que consequentemente estabelecem o network, construindo um processo de interação. 
VII Congresso Brasileiro de Informática na Educação (CBIE 2018)

Anais dos Workshops do VII Congresso Brasileiro de Informática na Educação (WCBIE 2018)

Para Barabási (2009), as redes têm seus movimentos e dinâmica ordenados por dois aspectos importantes - o crescimento e a conexão. O autor explica que a rede, normalmente, se inicia de um núcleo e tem seu crescimento devido à expansão dos nós, agregação de novos nós, que são conectados por nós ligados ao núcleo e ligados a nós ligados a outros nós, que, por sua vez, também estão ligados ao núcleo e assim sucessivamente. É como pensar em gerações de nós, a cada movimento, cada ação, novos nós são conectados aos nós já existentes.

Para Castells (2013), esse universo de comunicação online, que ganha outras dimensões para além da fala, possibilita uma política de "igualdade", que dá voz a todos, através dos canais de comunicação: escrita, áudio, vídeo. Independente do status que se ocupa na rede social, são livres as ações de postar, publicar, comentar, compartilhar, curtir, visualizar, todas podem expressar opinião de forma explícita ou implícita. O Advento das redes sociais na internet garantem autonomia aos sujeitos/usuários. Muitas vezes a primeira ação é desencadeadora de outras ações geram consequências de movimentos multiplicadores, que no âmbito da internet ganha amplitude e visibilidade. Esse movimento de propagação revela identidade e pertencimento do sujeito a grupos e/ou comunidades. Essas possibilidades de auto-organização e autonomia nas ações podem ser produtivas quando se trata de construção do conhecimento, essa cultura colaborativa pode ter desdobramentos positivos para aprendizagens em MOOC.

Cabe destacar que o MOOC se aproxima do comportamento dos usuários, no que tange a forma de comunicação, que hoje, pela forma que a internet está proposta, pela dimensão e uso das mídias sociais digitais, possibilitam uma comunicação e interação aberta, para além de plataformas. Cursos com propostas de serem abertos e on-line convidam os discentes para construção de comunidades, de grupos que buscam informações em comum. $\mathrm{O}$ aluno em MOOC pode interagir apenas com os materiais do conteúdo ou interagir com seus colegas. Para Rheingold (1996), através do advento da comunicação mediada por computadores, hoje, se reconhece o conceito de comunidades virtuais como resultado das formas de organização das pessoas para estabelecerem relações nos espaços digitais. Rheingold (1996, p. 20) fala:

As comunidades virtuais são agregados sociais que surgem da Rede, quando uma quantidade suficiente de gente leva adiante essas discussões públicas durante um tempo suficiente, com suficientes sentimentos humanos, para formar redes de relações pessoais no espaço cibernético.

Comunidades virtuais tratam-se de agrupamentos de pessoas conectadas por interesses, sujeitos que mantêm contato por buscarem algum tipo de recompensa ao manter o vínculo. Como por exemplo, acesso a informações privilegiadas, fazer parte de um grupo, ser identificado, entre outros. Essa ligação dentro do âmbito da internet é definida como grupo de pessoas que estabelecem relações sociais e se organizam através da comunicação mediada por computador, hoje mais especificamente, por mídias de redes sociais. 
VII Congresso Brasileiro de Informática na Educação (CBIE 2018)

Anais dos Workshops do VII Congresso Brasileiro de Informática na Educação (WCBIE 2018)

\section{Caminhos Metodológicos}

Tratamos de uma pesquisa que se caracteriza em quali-quantitativa, dentro de uma metodologia de estudo de caso. Os dados qualitativos foram explorados por mineração de dados, em que foi utilizado software SOBEK e posteriormente feita análise de conteúdo e os dados quantitativos foram explorados dentro da perspectiva de análise de redes sociais, para tanto foram utilizados os softwares UCINET e PAJEK. Tanto a análise qualitativa como a quantitativa foram fundamentais para a compreensão da learning analytics proposta nesta pesquisa.

O curso escolhido para coleta de dados foi o "Aprendendo a Aprender: Poderosas Ferramentas Mentais para ajudá-lo no domínio de temas complexos”, da Universidade de San Diego, na Califórnia, desenvolvido dentro da plataforma Coursera. O critério para definição do MOOC foi a plataforma; buscamos uma internacional, com vasta diversidade de ofertas de cursos, além da temática que pode ser explorada por diferentes áreas, o que supõe a participação diversificadas de alunos.

O campo de coleta de dados foram os fóruns propostos dentro da plataforma do MOOC. O instrumento de coleta de dados foram matrizes com os dados quantitativos, organizados em planilhas eletrônicas, exploradas em softwares específicos. As postagens dos alunos nos fóruns foram objeto de exploração para análise qualitativa, também exploradas em software específico.

Referente análise de redes sociais esta pesquisa desenvolveu matrizes, de rede Two Mode. Tratam-se das relações entre indivíduos, na perspectiva do ator, que através dos dados relacionais revelam ligações, laços ou conexões entre os alunos. A rede Two Mode é conhecida como rede de dois modos, bipartidas ou afiliação. Essa definição foi necessária devido à natureza dos dados no cenário do MOOC escolhido, representados por dois fóruns, diferentes tópicos de discussões e mais de 4.000 alunos matriculados. Como redes sociais são dinâmicas, ainda mais quando se trata de redes em espaços digitais, a coleta se configura por ser longitudinal. Ou seja, recortes de diferentes períodos da rede, cada momento selecionado representa uma fotografia das interações no MOOC.

A metodologia desta pesquisa busca, na luz da teoria da análise de redes sociais, da mineração de dados, em uma perspectiva de estudo das relações entre atores de uma rede, identificou padrões de interação social, através dos grafos gerados, essas interações permitiram analisar o comportamento dos sujeitos dentro de uma plataforma de aprendizagem.

\section{Análise de Dados}

O MOOC escolhido foi organizado com prazos nas atividades; todos os alunos que desejosos em concluir o curso precisam respeitar os prazos estipulados para atividades previstas em cada módulo. De acordo com cronograma previsto pelo curso, este deve ser concluído no período de um mês. Os módulos são sequenciais e lineares, conforme o aluno acessa os conteúdos disponibilizados cronologicamente outros módulos são liberados. 
VII Congresso Brasileiro de Informática na Educação (CBIE 2018)

Anais dos Workshops do VII Congresso Brasileiro de Informática na Educação (WCBIE 2018)

As definições pela coleta de dados tiveram início com a leitura na íntegra de todas as postagens dos fóruns, optou-se por selecionar dois, por considerar que esses eram os fóruns com postagens mais relacionadas ao conteúdo. Os dados desta pesquisa foram coletados através das postagens realizadas pelos alunos nos fóruns dentro da plataforma Coursera, organizados da seguinte maneira:

1) fórum - grupo de estudo;

2) fórum - discussão geral.

Foram realizadas coletas de dez em dez dias, durante três meses, que totalizaram nove momentos de fotografias, que revelam os registros do que estava acontecendo no curso no período das extrações. Para cada coleta foram construídas matrizes específicas. Essas matrizes serviram de registro sobre o que os alunos postaram nos fóruns diretamente e nos tópicos de discussões dentro de cada fórum. Durante a coleta de dados no MOOC, identificamos que a grande maioria dos alunos se matriculam, mas não necessariamente finaliza o curso, o que impossibilita o acompanhamento e learning analytics. Isso fica evidente ao identificar o grande número de alunos matriculados versus número de interações nos espaços de comunicação e o pequeno número que concluiu todas as atividades propostas.

O MOOC que observado teve mais de 4.000 alunos matriculados, aproximadamente 229 alunos interagiram semanalmente nos fóruns de discussões e 19 alunos finalizam todas as tarefas e apenas 2 alunos foram concluintes da atividade final, que tinha como proposta corrigir a tarefa do colega.

\subsection{Análise das Redes Sociais}

A análise de redes sociais teve seu olhar direcionado para dois focos: a) métricas relacionadas ao nó (aluno) que destacam: grau de intermediação e centralidade; b) métricas relacionadas a rede (MOOC): densidade e centralização. Cada fórum tem um assunto geral, mas dentro de cada assunto geral há vários desdobramentos, alguns com presença de intercâmbios (trocas) entre os alunos, outros com ausência de trocas sociais.

Foram 9 momentos de extração dos dados, em que coletamos número de postagens por fórum e número de postagens por tópico de discussão dentro do fórum. Os dados encontrados durante cada um dos períodos apresentaram pouca diferença, o que nos possibilita afirmar que o número de postagens nos fóruns fica entorno de $60 \mathrm{a}$ 65 .

A rede analisada apresenta uma densidade relevante de acordo com número de sujeitos conectados. Com densidade igual entorno de 1,28 a 1,70, que significa uma rede de aproximadamente 205 a 339 atores (alunos ativos no fórum). Estas medidas revelam uma rede de conexão razoável para contexto de cibercultura. No entanto, devido ao número massivo de alunos matriculados (4.000), esperava-se um número mais elevado. $\mathrm{Na}$ imagem a seguir, é possível ver a dimensão das postagens que recebem comentários. Cada quadrado representa uma postagem, quando maior, mais comentários. 


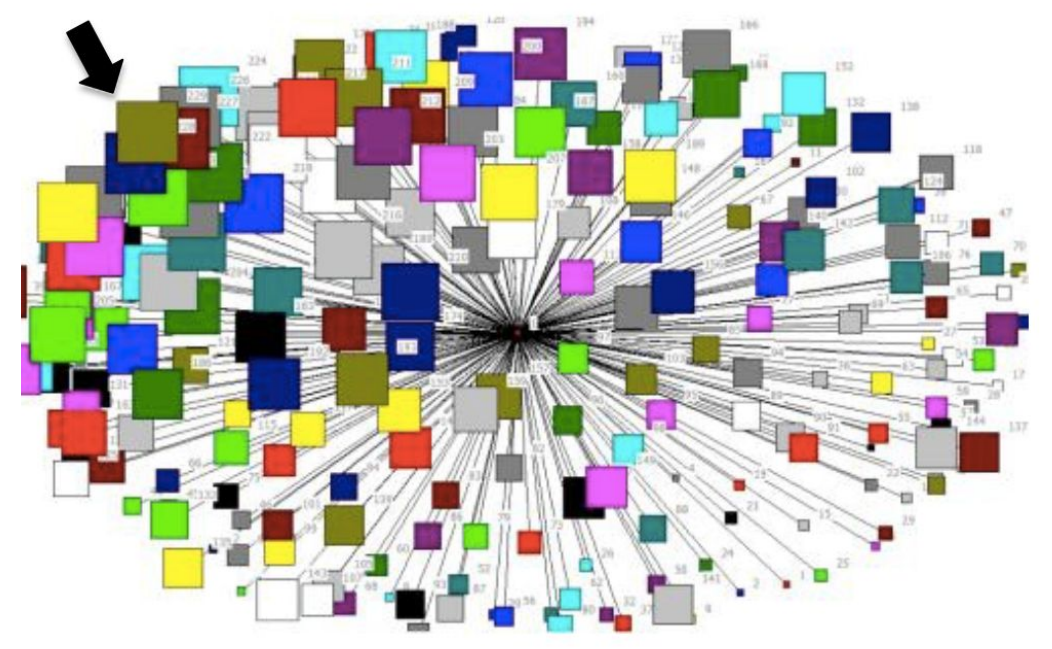

Figure 1. Grafo postagem dos alunos

A identificação dos atores é representada através do papel em que assumem dentro da rede social, especificamente dentro dos fóruns: 1) fórum grupo de estudo do conteúdo; 2) fórum de discussão geral. É possível identificar que há um percentual considerável de alunos com desdobramento em suas postagens, ou seja, alunos com comentários em suas postagens. Representados pelos quadrados maiores no grafo apresentado. $\mathrm{Na}$ imagem a seguir conseguimos através do indicador de centralidade (degree) identificar os tópicos dos fóruns com maior postagem. Há 8 tópicos dentro do fórum com maior número de comentários. Os tópicos 2, 4, 7, 9, 16, 18 e 19 foram as postagens com menor número de comentários dos alunos. $\mathrm{Na}$ imagem a seguir conseguimos visualizar os valores correspondentes a centralidade da rede do MOOC:

\begin{tabular}{|c|c|c|c|c|c|c|}
\hline & & $\begin{array}{r}1 \\
\text { Degree }\end{array}$ & 2-Local & Eigenvect ${ }^{3}$ & $\begin{array}{r}4 \\
\text { Closeness }\end{array}$ & $\begin{array}{r}5 \\
\text { Betweenne }\end{array}$ \\
\hline 1 & PRETICA APRENDIZADO & 0.013 & 0.000 & 0.005 & 0.306 & 0.017 \\
\hline 2 & PRAZO ATIVIDADES & 0.003 & 0.000 & 0,000 & 357.000 & 0,000 \\
\hline 3 & VÊDEOS DUBLADOS & 0.032 & 0.001 & 0.001 & 0.252 & 0.051 \\
\hline 4 & DEVIDAS TEC. POMOD. & 0.003 & 0.000 & 0,000 & 357.000 & 0,000 \\
\hline 5 & RESUMO CURSO EM HO & 0.010 & 0.000 & 0,000 & 119.000 & 0.800 \\
\hline 6 & CERTIFICADO CURSO & 0.010 & 0.000 & 0.000 & 0.224 & 0.011 \\
\hline 7 & INCENTIVO APRENDER & 0.003 & 0.000 & 0,000 & 357.000 & 0,000 \\
\hline 8 & POR QUE APRENDER? & 0.671 & 0.450 & 0.994 & 0.648 & 0.798 \\
\hline 9 & PROBLEMA SITE & 0.003 & $\begin{array}{l}0.080 \\
0.436\end{array}$ & 0,000 & 357.008 & 0,000 \\
\hline 10 & RECLAMABEO COLEGAS & 0.006 & 8.000 & 0.000 & 0.230 & 0.002 \\
\hline 11 & EFICECIA POMODORO & 0.006 & 0.080 & 0.000 & 0.177 & 0.006 \\
\hline 12 & TRAD LIVRO BARBARA & 0.016 & 8.080 & 0.000 & 0.237 & 0.011 \\
\hline 13 & TEC. CONCENTRAQ60 & 0.022 & 0.081 & 0.005 & 0.350 & 0.028 \\
\hline & PROBLEMA DE ACESSO & 0.048 & $\begin{array}{l}0.001 \\
0.082\end{array}$ & 0.015 & $\begin{array}{l}0.317 \\
0.317\end{array}$ & 0.066 \\
\hline 15 & REGRAS P/ BOM ESTUDO & 0.051 & 0.083 & 0.017 & 0.367 & 0.100 \\
\hline 16 & DICAS DE VIDEOS & 0.003 & 0.000 & 0,000 & 357.008 & 0,000 \\
\hline 17 & PLATAFORMA EBOOK & 0.045 & 0.002 & 0.011 & 0.358 & 0.065 \\
\hline 18 & $\begin{array}{l}\text { APRESENTAEQO } \\
\text { APRSE }\end{array}$ & 0.003 & 0.000 & 0.000 & 0.217 & 0,000 \\
\hline 19 & APRESENTAQ60 & 0.003 & 0.000 & 0,000 & 357.000 & 0,000 \\
\hline 20 & TROCA DE APRENDIZADO & 0.016 & 0.080 & 0.005 & 0.325 & 0.018 \\
\hline 21 & APRESENTABEO & 0.006 & 0.000 & 0.005 & 0.324 & 0.006 \\
\hline 22 & APRES. NOVOS METOD. & 0.010 & 0.080 & 0,000 & 119.000 & 0.000 \\
\hline 23 & DICAS LIVROS & 0.163 & $\begin{array}{l}8.027 \\
0.027\end{array}$ & 0.105 & 0.488 & 0.222 \\
\hline
\end{tabular}

Figure 2. Comentários por tópicos no fórum 
VII Congresso Brasileiro de Informática na Educação (CBIE 2018)

Anais dos Workshops do VII Congresso Brasileiro de Informática na Educação (WCBIE 2018)

\subsection{Mineração de Dados e Análise de Conteúdo}

Realizamos a análise de conteúdos através da perspectiva de Bardin (1979) e de Moraes (1999), ambos tratam da um ciclo de análise, construído, principalmente, de três elementos: unitarização, categorização e comunicação. Antes do processo de coleta e análise das postagens nos fóruns, foi necessário fazer um levantamento prévio das discussões presentes em cada um. O total de postagens coletadas foram 4.071, a exploração do conteúdo das postagens possibilitaram identificar duas categorias: 1) Trocas de Informação e 2) Dicas e Intercâmbios de Aprendizagens.

A registro de postagens no fórum Grupo de Estudo foi disparada a partir da dica de um livro, como sugestão de um dos alunos para grupo, referente a uma leitura complementar. O tópico "trocas de informações e dicas" é um dos espaços do MOOC que mais revelam benefícios, que em especial trata de acesso a dica de estudo e conteúdo complementar. A maioria das postagens remete ao grupo de forma geral e não necessariamente a um aluno específico.

O fórum de discussão específico da tarefa obrigatório da semana inicial teve duas postagens mais evidentes, uma com 69 visualizações e 6 comentários, outra com 374 visualizações e 59 comentários. A ação predominante é voltada ao visualizar e não necessariamente responder ou comentar uma postagem.

A tarefa obrigatória poderia ser desenvolvida com recursos digitais, com apoio de vídeos, imagens, animações, jogos entre outros. Em três meses foram identificadas 19 entregas, destas 5 foram planejadas com recursos digitais interativos: 2 blogs, 1 jogo no scratch, 1 prezzi, 1 vídeo. As demais atividades foram entregues em arquivos fechados de PDF. No entanto, das 19 atividades entregues, apenas 2 foram corrigidas pelos colegas, conforme orientação do MOOC, o que revela que apenas dois alunos concluíram a proposta do curso.

O fórum de discussão da tarefa obrigatória teve 1 postagem, com 16 visualizações e nenhum comentário. Sendo uma postagem de desabafo e explicações sobre encaminhamento referente às expectativas com as atividades do MOOC. Mesmo sendo uma proposta de MOOC, com conteúdo aberto na internet com mais de 4.000 alunos conectados na mesma rede, ainda assim, a troca estabelecida entre os alunos revela predominância na interação entre aluno e plataforma e não entre alunos e alunos.

O papel social do MOOC, devido ao modelo pedagógico do curso, não está voltado a gerar intercâmbios de collaborative learning, porque interação estabelecida é entre aluno/conteúdo. Desenvolver uma learning network exige que o aluno busque em sua bagagem os conhecimentos adquiridos, os momentos vivenciados, que de alguma forma possam ser compartilhados com seus colegas/pares.

\section{Conclusões}

O MOOC analisado teve 4.000 alunos, sendo os que 229 representam a densidade da rede, que representam o número de conexões. A quantidade de 229 alunos para um cenário de 4.000 representa um número baixo diante dos alunos matriculados. Desse número de 229 são identificados 2 alunos como centrais na rede, ou seja, são os alunos 
VII Congresso Brasileiro de Informática na Educação (CBIE 2018)

Anais dos Workshops do VII Congresso Brasileiro de Informática na Educação (WCBIE 2018)

que mais recebem e emitem conexões. Esse número de centralidade é baixo para o número de densidade identificado.

Atribuímos que esse modelo pedagógico de MOOC deixa o convite aos alunos assumirem o papel de intermediação pedagógica e de indicação de materiais, mas esses ficam "amarrados" à autonomia do aluno que nem sempre se sente confortável em assumir essa postura. $\mathrm{O}$ que nos provoca a dizer que o MOOC analisado não gera intercâmbios que efetivamente emergem das aprendizagens, mesmo esses alunos estando conectados por uma plataforma que tem recursos de rede social. A interação predominantemente identificada é de aluno/conteúdo e não de troca social. Cabe destacar que isso não significa falta de aprendizagem, indica limitação nas interações sociais estabelecidas entre aluno/aluno.

Dessa forma, consideramos que o papel social do curso massivo aberto e on-line é disponibilizar conteúdo de qualidade, fornecer informação, mas não necessariamente servir como espaço de trocas sociais/intercâmbios.

É importante destacar que não há dúvidas de que os processos de ensino e aprendizagens explorados no curso têm desdobramentos diferentes da modalidade Educação a Distância. Enquanto, por legislação, as propostas de EaD contam com a presença de um professor/tutor, no MOOC, não há essa obrigatoriedade. O que consideramos ter reflexo direto no comportamento dos alunos diante da proposta pedagógica do curso.

Identificamos que a grande maioria dos alunos acessa os módulos específicos de conteúdo do MOOC e sai da plataforma logo que consegue as informações necessárias. Há um processo de seleção de informação, que se desdobra na escolha de fazer ou não todos os módulos.

O modelo pedagógico do MOOC apresentava seus módulos articulados em sequência, o que exigia a navegação do aluno de forma linear. Umas das possibilidades indicadas por este estudo é a construção do planejamento dos módulos independentes entre si, podendo ser realizados módulos individuais. A possibilidade de ter acesso a toda a proposta e depois escolher os módulos que lhe interessa pode ser um indicador de um novo formato de curso autoinstrucional, em que os alunos escolham o conteúdo do módulo de acordo com seu interesse e assim possam desenvolver personal learning. Por conta dessa possibilidade de acesso em transitar pelas informações, o aluno pode assumir um papel de autonomia na escolha do conteúdo que considera pertinente para seu interesse. O papel assumido é muito mais uma postura de aluno consumidor, em que acessa, analisa o todo e seleciona o que lhe interessa, do que papel de aluno/tutor, que assume processos de aprendizagens sociais.

Se a intencionalidade em criar um MOOC é collaborative learning então o desafio está posto, pois as trocas em cursos massivos são dependentes de intermediação de um professor/tutor. Justamente porque a sociedade conectada revela que diante das possibilidades de MOOC, Ensino On-line, Híbrido e EaD, ainda estamos em processo de constituição, enquanto alunos. São poucos os alunos que assumem uma postura de autonomia e organização sobre personal learning. Muitos alunos ainda dependem da "permissão"do professor/tutor para agir, para colaborar, para trocar. A sociedade conectada apresenta um perfil de processos de aprendizagens baseado nos imigrantes 
VII Congresso Brasileiro de Informática na Educação (CBIE 2018)

Anais dos Workshops do VII Congresso Brasileiro de Informática na Educação (WCBIE 2018)

digitais, ainda estamos em processos de transformações. Mas isso é discussão para outras pesquisas.

Por fim, concluímos que MOOC são excelentes canais para consulta de informação, seleção de conteúdo, pois disponibilizam materiais planejados por professores, geralmente ligados ao ensino superior, o que contribui com à qualidade. $\mathrm{E}$ reconhecemos os desafios de uma pesquisa longitudinal, que limita o acompanhamento de processos de aprendizagens. Esperamos que essa pesquisa possa desencadear outros estudos, que possam apontar estratégias de planejamentos pedagógicos não apenas para MOOC, mas para espaços digitais explorados em tempos de sociedade conectada.

\section{References}

BARABÁSI, A. L. , (2009) Linked: a nova ciência dos networks. Como tudo está conectado a tudo e o que isso significa para os negócios, relações sociais e ciências. São Paulo: Editora Leopardo.

BARDIN, Laurence. (1995)Análise de conteúdo. (1979) Lisboa: Edições 70.

CASTELLS, Manuel (2001). A sociedade em rede. Vol. I. 8. ed. São Paulo: Paz e Terra. (2013). Redes de Indignação e esperança. Rio de Janeiro, Editora Zahar.

MORAES, Roque. (1999). Análise de conteúdo. Revista Educação, Porto Alegre, v. 22, n. 37, p. 7-32.

PISUTOVA, K. (2012). Open Education, International Conference on Emerging eLearning Technologies and Applications ICETA.

RHEINGOLD, H. (1996). A Comunidade Virtual. Lisboa: Gradiva.

- (1994). La Comunidad Virtual: Una Sociedad sin Fronteras. Gedisa Editorial. Colección Limites de La Ciência. Barcelona. . (2007). The Virtual Community: Homesteading at the Electronic Frontier. 